\title{
Production of Biodiesel from Waste Vegetable Oil via KM Micro-mixer
}

\section{Elkady MF ${ }^{1,2 *}$, Ahmed Zaatout ${ }^{3}$ and Ola Balbaa ${ }^{3}$}

${ }^{1}$ Chemical and Petrochemical Engineering Department, Egypt-Japan University of Science and Technology, New Borg El-Arab City, Alexandria, Egypt ${ }^{2}$ Advanced Technology and New Materials and Research Institute (ATNMRI), City of Scientific Research and Technological Applications, Alexandria, Egypt

${ }^{3}$ Chemical Engineering Department, Faculty of Engineering, Alexandria University, Alexandria, Egypt

\begin{abstract}
The production of biodiesel to substitute fossil fuels has been challenging to apply in many countries especially developing countries. Given the importance of this fact, this study includes the production of biodiesel from waste vegetable oils by pre-treatment followed by transesterification reaction with methanol using a KM micro-mixer reactor. KM micro-mixer happened to give noticeable enhancement for the production of biodiesel quality compared to the normal batch reactor at optimum conditions. The parameters affecting biodiesel production process such as alcohol to oil molar ratio, catalyst concentration, the presence of tetra-hydrofuran (THF) as a co-solvents and the volumetric flow rates of inlet fluids were optimized. The properties of the produced biodiesel were compared with its parent waste oil through different characterization techniques. The presence of methyl ester groups at the produced biodiesel was confirmed using both the Gas chromatography-mass spectrometry (GC-MS) and infrared spectroscopy (FT-IR). Moreover, the thermal analysis of the produced biodiesel and the comparable waste oil indicated that the product after the transesterification process began to vaporize at $120^{\circ} \mathrm{C}$ which makes it lighter than its parent oil which started to vaporize at around $300^{\circ} \mathrm{C}$. The maximum biodiesel production yield of $97 \%$ was recorded using 12:1 methanol to oil molar ratio in presence of both $1 \% \mathrm{NaOH}$ and THF/methanol volume ratio 0.3 at $60 \mathrm{~mL} / \mathrm{h}$ flow rate.
\end{abstract}

Keywords: Biodiesel; KM micro-mixer; Transesterification; Methyl esters; Waste oil

\section{Introduction}

The idea of using alternative fuels has been widely spreading for many years now as a replacement for Fossil fuels. The importance of this idea came from the large scale of utilization of Fossil fuels in mechanical power generation various sectors, like agriculture, commercial, domestic and transport, also the fact of the continuous rise in Fuels cost and their eventual vanish [1].

The use of vegetable oils and their derivatives was found one of the reasonable solutions. However, the direct use of Vegetable oils in diesel engines was found impractical due to several factors, such as the high viscosity, acid composition and free fatty acid content. Accordingly, they require further modifications for effective use [2]. Undergoing transesterification reaction is the most favorable for decreasing oil's viscosity and producing what so called "Biodiesel fuel" [3]. Biodiesels are mono-alkyl esters of long chain fatty acid derived from renewable lipid feedstock. The interest of this alternative energy resource is that the fatty acid methyl esters, known as biodiesel, have similar characteristics of petro-diesel oil which allows its use in compression motors without any engine modification [4]. However, using vegetable oil to replace fuel caused the food versus fuel issue all over the world [5]. So the idea of using waste vegetable oil (WVO) has been introduced as an economical solution which also gives a waste management solution [6].

Transesterification is a process of transforming triglycerides in vegetable oils into a mixture of fatty acid esters using alcohol and catalyst to speed up this reaction to the right side and to obtain high biodiesel yields. Methyl or ethyl esters are obtained, with much more similar properties to those of conventional diesel fuels. The main byproduct obtained is glycerol. Figure 1, shows the general equation of transesterification reaction. The most common alcohol used for biodiesel production is methanol because of its price and conversion rates. Other alcohols can be used too, such as plant based ethanol, propanol, isopropanol and butanol [3]. In presence of excess alcohol, the foreword reaction extends beyond the reverse reaction. Many catalysts could be utilized in the process, however, it was confirmed that transesterification is completed faster using an alkali catalyst [7]. The mechanism of transesterification shows some challenges regarding this process, starting from the limitation of reaction rate by mass transfer between the immiscible oil and alcohol besides the reversibility of the transesterification itself which limits the conversion and consequently increases the reaction time and cost [4].

These challenges of transesterification reaction happened to appear clearly using conventional batch reaction processes. Many alternatives have been proposed to undergo the reaction in a more effective way through improving mixing rate, enhancing heat and mass transfer of the reaction and decreasing cost and time consumed [8]. For instance, changing the process performance using super critical conditions through applying high temperature and pressure enhance the process mass transfer [2]. Moreover, proposing different catalysis approaches such as heterogeneous or enzyme catalysis improve the process reaction rate. Also, changing the process design and mixing concepts such as using ultrasonic homogenizers increase both the process mass and heat transfer [9]. The methods mentioned were found quiet effective for solving the problems facing transesterification like time consumption, soap formation, etc. However, energy consumption rate increases significantly and therefore the total cost of the process increases. Another proposed change in the process design was the

*Corresponding author: Elkady MF, Advanced Technology and New Materials and Research Institute (ATNMRI), City of Scientific Research and Technological Applications, Alexandria, Egypt, Tel/Fax: 444-40-2577544; E-mail: marwa.f.elkady@gmail.com

Received Mar 11, 2015; Accepted April 07, 2015; Published April 14, 2015

Citation: Elkady MF, Zaatout A, Balbaa O (2015) Production of Biodiesel from Waste Vegetable Oil via KM Micro-mixer. J Pet Environ Biotechnol 6: 218 doi:10.4172/2157-7463.1000218

Copyright: @ 2015 Elkady MF, et al. This is an open-access article distributed under the terms of the Creative Commons Attribution License, which permits unrestricted use, distribution, and reproduction in any medium, provided the original author and source are credited. 


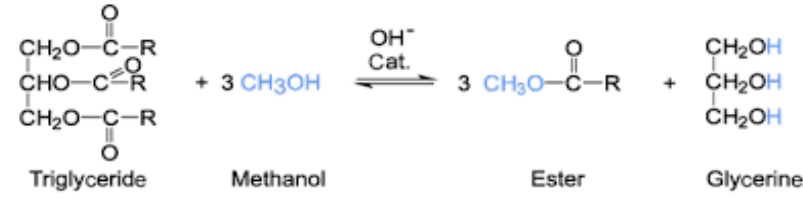

Figure 1: General equation of transesterification.

use of microreactors for achieving transesterification reaction within short time. Generally, micro reactors are micro structured reactors with micro-channels, they have various shapes and different structures designed for better mixing and completing the reactions. Simple microscale capillaries were the first reported microreactors used in biodiesel synthesis [10]. Other advanced microreactors were later fabricated using wide variety of materials and different manufacturing techniques [10]. As previously discussed, the mass transfer of the reacting triglycerides from the oil phase towards the methanol/oil interface limits the rate of methanolysis reaction and controls the kinetics at the beginning of the reaction [11]. Also the droplet size highly affects the methyl ester yield in this reaction. Accordingly, microreactors were utilized at the transesterification reaction holding the advantage of high volume/surface ratio, short diffusion distance, fast and efficient heat dissipation and mass transfer [12]. By this role microreactors promote the overall volumetric mass transfer coefficient of methyl esters due to the increase of the specific interfacial area by decreasing the droplet size. This eventually results in the increase of reaction rate for triglycerides [13]. The KM micro- mixer has been tested for mixing two immiscible fluids and was found superior over other mixers designs. Also it provides high throughput and stable operation in a wide range of flow rate ratios for the two reactant fluids [14]. In this investigation, a KM micro-mixer has been used as a microreactor for transesterification of waste vegetable oil with methanol in presence of $\mathrm{NaOH}$ as catalyst. The influences of transesterification process variables such as alcohol to oil molar ratio, catalyst concentration, volumetric flow rate and effect of an organic co-solvent presence were optimized. GC-MS analysis was utilized for characterization and identification of the produced biodiesel.

\section{Materials and Method}

\section{Materials}

Waste Vegetable oil was purchased from a local restaurant as a source of triglycerides for transesterification reaction. The alcohol selected was methanol (99.8\%, Sigma-Aldrich.). Other utilized chemicals for transesterification process are from analytical grades such as sodium hydroxide (99\%, Sigma-Aldrich), acetic acid (98\%, SigmaAldrich) and tetra-hydrofuran (anhydrous 99\%, Sigma-Aldrich).

\section{Waste vegetable oil pretreatment}

The waste vegetable oil (WVO) was first filtered to remove bits of food residues using a glass Büchner funnel filtration system then it was subjected to an acid catalyzed esterification process in order to maintain free fatty acid content lower than $1 \%$ [15].

\section{Experimental setup}

The KM micro-mixer proposed for this investigation consists of 3 stainless steel plates, inlet, mixing and outlet plates holding fourteen micro-channels fabricated for fluid streams. Dimensions of the micromixer are shown in Table 1. The mixer has 2 inlets for two different reactant fluids. The fluids are transferred to the mixing plate through annular channels where fourteen micro-channels are present.

Micro-channels are fabricated by Micro Electric Discharge Machining $(\mu-E D M)$. The stream of each fluid was divided into half of the total number of micro channels. The two divided fluids meet at the center of the mixing plate and are immediately mixed. The diameter of the mixing zone was found to be $220 \mu \mathrm{m}$. Finally, the outlet plate has a hole for the exit of the mixed fluid at the center of the plate, the exit fluid hole $(200 \mu \mathrm{m})$ is smaller than the diameter of the mixing zone to accelerate the mixing process [14].

The experiment is set as shown in Figure 2. The KM mixer is immersed in a water bath to provide the required reaction temperature. Two Syringe pumps (KD Scientific, KDS100, USA) were used for feeding the inlet reactant fluids.

\section{Biodiesel production process using KM mixer}

Two reactant fluids were fed via syringe pumps into the designed experimental setup, the first is the preheated oil at specific temperature, and the second is the mixture of methanol, sodium hydroxide and THF. The proper amount of sodium hydroxide was dissolved completely in methanol to avoid clogging the micro channels at the KM mixer with solid particles. The amount varied from $0.5 \%$ to $2 \%$ (wt/wt of oil) to elucidate the most suitable amount that attains the highest biodiesel production yields. The reactants feeding rates were changed over a wide range from $20 \mathrm{~mL} / \mathrm{h}$ to $200 \mathrm{~mL} / \mathrm{h}$ to investigate the influence of residence time on the biodiesel production process. The reactants molar ratio was optimized to determine the most proper mixing ratio. The KM mixer that includes the process reactants was maintained at specific water bath temperature $70^{\circ} \mathrm{C}$. The experiments were usually repeated two times to determine the experimental error. At the KM mixer outlet the product is collected after reaching steady state in a beaker containing appropriate amount of acetic acid to neutralize the excess alkaline catalyst and stop the reaction. The product of the reaction is placed in a separating funnel to be separated into two clear phases. The biodiesel which is the main product separated as upper light-colored phase while the lower dark phase is mainly glycerol. The upper phase was washed after separation with distilled water for excess catalyst and glycerol removal then it was heated up to $70^{\circ} \mathrm{C}$ to vaporize the excess solvent. The remaining main product was then characterized using GC-MS analysis to confirm oil conversion and identify biodiesel production yield.

\section{Characterization of produced biodiesel}

In order to characterize the quantity and the quality of the produced biodiesel several techniques were utilized. The volume of biodiesel product was first measured and the volume yield percentage was calculated according to the following equation (1):

Volume Yield \%= (volume of product/volume of oil fed) X 100

The fatty acid methyl esters (FAMEs) in the produced biodiesel were then characterized and identified using Gas chromatography mass spectrometry (GCMS-QP2010Ultra, Shimadzu, Japan) fitted with 5MS column (30m, $0.25 \mathrm{mmID}, 0.25 \mu \mathrm{m})$. GC-MS analysis mainly identifies the quality and quantity of the produced biodiesel resembled in the methyl esters present in the product sample. This analysis technique also gives the distribution area for each component in the produced sample. Table 2 shows the GC-MS configuration used for biodiesel analysis. The total yield from the biodiesel was finally calculated according to equation (2): 


\begin{tabular}{|c|c|c|c|c|}
\hline Internal sketch & $\begin{array}{c}\text { Number of } \\
\text { channel }\end{array}$ & $\begin{array}{c}\text { Channel } \\
\text { width }\end{array}$ & $\begin{array}{c}\text { Diameter of } \\
\text { mixing zone }\end{array}$ & $\begin{array}{c}\text { Diameter } \\
\text { of Outlet }\end{array}$ \\
\hline & & & & \\
\hline & & & & \\
\hline & 14 & $50 \mu \mathrm{m}$ & $220 \mu \mathrm{m}$ & $200 \mu \mathrm{m}$ \\
\hline
\end{tabular}

Table 1: Dimensions of KM micro-mixer.

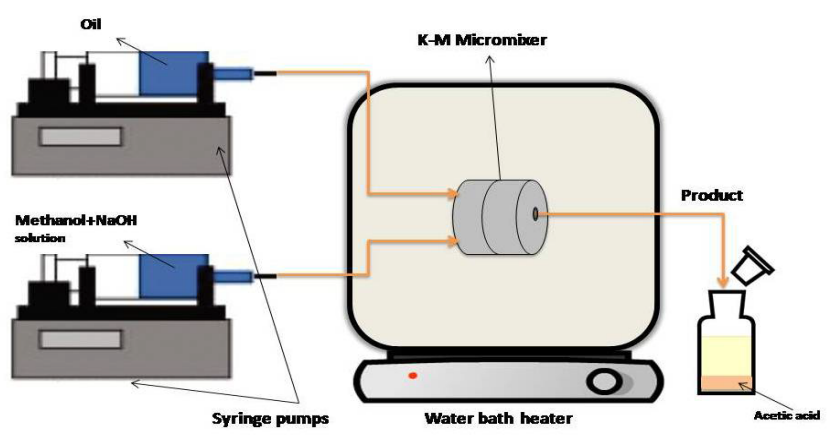

Figure 2: Schematic view of the KM mixer system.

\begin{tabular}{|c|c|}
\hline & Injector \\
\hline Inlet temperature & $200^{\circ} \mathrm{C}$ \\
Sample size & $2 \mu \mathrm{l}$ \\
Split ratio & 50 \\
\hline & Column temperature program \\
\hline Initial temperature & $50^{\circ} \mathrm{C}$ \\
Rate 1 & $15^{\circ} \mathrm{C} / \mathrm{min}$ to $180^{\circ} \mathrm{C}$ \\
Rate 2 & $7^{\circ} \mathrm{C} / \mathrm{min}$ to $230^{\circ} \mathrm{C}$ \\
Rate 3 & $10^{\circ} \mathrm{C} / \mathrm{min}$ to $280^{\circ} \mathrm{C}$ \\
\hline & Detector \\
\hline Type & Mass Spectrometer \\
\hline Interface temperature & $200^{\circ} \mathrm{C}$ \\
\hline & Column \\
\hline Type & HP-5MS $(30 \mathrm{~m}, 0.25 \mathrm{mmID}, 0.25 \mu \mathrm{m})$ \\
\hline Flow rate & $3 \mathrm{~mL} / \mathrm{min}$ \\
\hline
\end{tabular}

Biodiesel yield $\%=$ FAMEs percentage from GC analysis X Volume yield (2)

Thermal analysis of the prepared biodiesel and its parent waste oil were carried out using thermal gravimetric analysis (TGA-50, Shimadzu, Japan) with a heating rate of $20^{\circ} \mathrm{C} / \mathrm{min}$ under the flow of nitrogen gas, starting from ambient condition up to $800^{\circ} \mathrm{C}$.

Fourier transform infrared spectroscopy (Vertex 70, Germany) was utilized to compare the main function group presence in the produced biodiesel and its parent waste oil. The I.R. spectrum was scanned through a wave length range of $4000-400 \mathrm{~cm}^{-1}$. Both the TGA and FT-IR techniques were used for quantitative and qualitative analysis respectively of the product and to confirm GC-MS results.

\section{Results and Discussion}

\section{Biodiesel production using KM mixer}

In order to optimize the processing parameters affecting biodiesel production according to the main equation of the transesterification process using KM mixer. The influence of molar ratio of methanol to oil, catalyst concentration, volumetric flow rate and presence of THF were investigated and the product was analyzed using GC-MS analysis.
Effect of methanol to oil molar ratio: The most effective variable affecting the methyl ester production yield during the transesterification reaction is the molar ratio of alcohol to waste vegetable oil. Since transesterification is an equilibrium reaction, a large excess of alcohol is required for the reaction to move forward and avoid the reversible reaction [16].

The biodiesel production has been investigated over a studied reactants molar ratios of methanol to oil from $6: 1$ up to $48: 1$. It was evident from Figure 3a that 6:1 reactants ratio recorded the lowest biodiesel conversion compared with 12:1 molar ration that attained the maximum biodiesel conversion. The increase in alcohol to oil molar ratio above 12:1 declines the biodiesel conversion. This is due to the reversibility behavior of transesterification reaction [17]. Figure 3b illustrates GC-MS of biodiesel produced at 24:1 methanol to oil molar ratio. It showed the appearance of a clear peak at 4.8 minutes retention time. This peak is verified to be glycerol. This result indicates the difficulty in separating the two produced layers of biodiesel and glycerol at high methanol to oil molar ratios regarding to the solubility of glycerol in excess methanol. This result proved that increasing the molar ratio higher than 12:1 was unflavored for the transesterification process using KM mixer.

Effect of catalyst concentration: The most common catalysts used for transesterification reaction are the alkali catalysts, like sodium and potassium hydroxides because they both react with the triglycerides to break them apart so that methanol can bond with the fatty acids and produce biodiesel. However, sodium hydroxide was selected to be utilized as catalyst in this investigation due to its low cost and availability [2].

A wide concentration range of sodium hydroxide from $0.5 \%$ to $2 \%$ (wt/wt of oil) has been tested as a catalyst that was premixed with methanol to form sodium methoxide $\left(\mathrm{CH}_{3} \mathrm{Na}\right)$. The behavior of $\mathrm{NaOH}$ concentration regarding to the biodiesel production yield was shown in Figure 4a. Incomplete biodiesel conversion was indicated using $0.5 \%$ catalyst concentration. The highest biodiesel yield of $95 \%$ was achieved using $1 \%$ catalyst concentration. It was indicated from Figure $4 \mathrm{a}$ that as $\mathrm{NaOH}$ concentration increased above $1 \%$ significant decrease in the biodiesel yield was recorded. This result may be explained due to the soap formation owing to the excess of $\mathrm{NaOH}$ that reacts with oil fatty acids producing sodium oleate (soap) and water according to the following equation [18].

This prediction was confirmed from Figure $4 \mathrm{~b}$ that investigates the GC-MS analysis for the biodiesel produced using $2 \%$ catalyst concentration. A clear peak of soap formation was indicated from this figure at six minutes retention time. Accordingly $1 \%$ wt/wt of $\mathrm{NaOH}$ was selected as the optimum catalyst concentration for high conversion biodiesel product.

Effect of reactant volumetric flow rate: Generally, the biodiesel production yield was enhanced through improvement the reactants residence time. The KM micro-mixer characterized by its rapid mixing property resulting from small micro-channel size. These small micro-channels provide fast and efficient mass transport rate versus short diffusion distance and also offer high surface to volume ratios, consequently the reaction residence time parameter at the $\mathrm{KM}$ micro-mixer is positively affected [10]. Figure 5 shows the behavior of changing the volumetric flow rates of reactants introduced into the KM micro-mixer. It was elucidated from this figure that the reactants flow rates of 20, 40 and $60 \mathrm{~mL} / \mathrm{h}$ of two inlet reactants gave approximately equal biodiesel production yield around $96 \%$. Further increase at the 


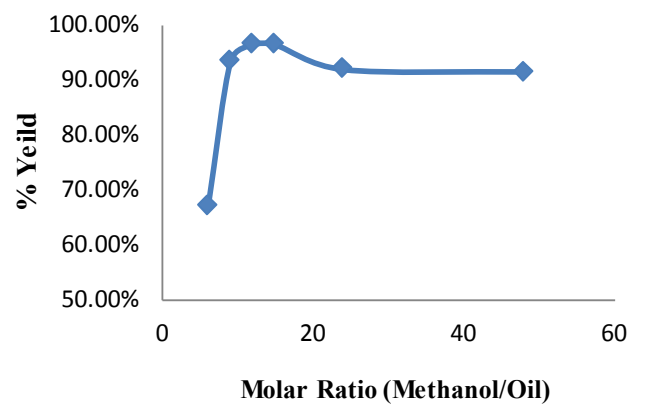

Figure 3a: Effect of Methanol to oil molar ratio on percentage biodiesel yield.

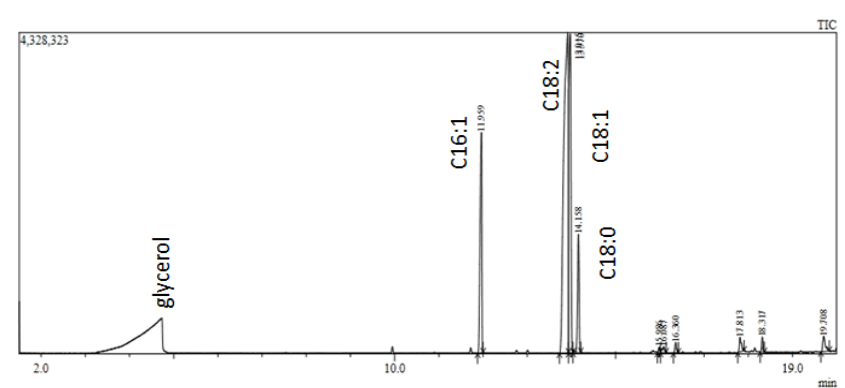

Figure 3b: GC-MS of biodiesel produced using 24:1 methanol:oil molar ratio.

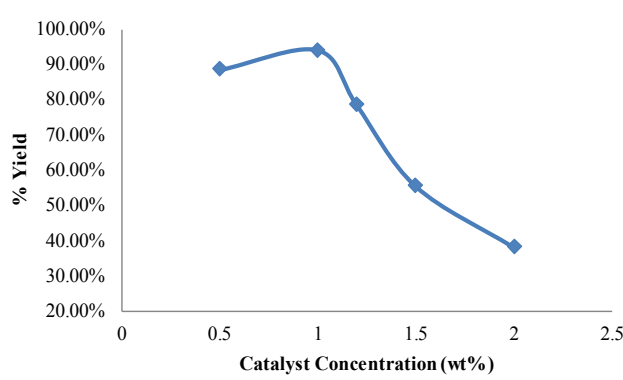

Figure 4a: Effect of $\mathrm{NaOH}$ concentration with respect to oil weight on percentage biodiesel yield.

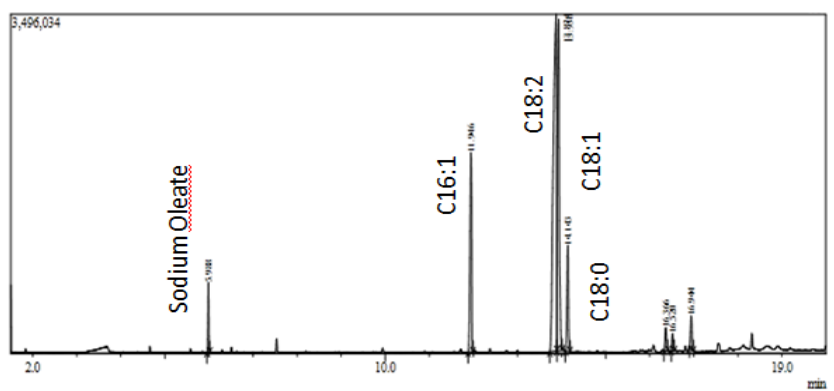

Figure 4b: GC-MS of biodiesel produced using $2 \% \mathrm{NaOH}$ catalyst concentration.

reactants flow rates above $60 \mathrm{~mL} / \mathrm{h}$ the percentage biodiesel production yield showed obvious drop. This behavior may be explained by stating that for KM Mixer, higher flow rates will result in increasing the pressure drop inside the reactor due to the small mixing zone diameter of the micro-mixer which affects the completion of the transesterification reaction [10]. Also very low flow rates were not durable for KM mixer causing it to lose its main privilege which is decreasing the reaction time. Accordingly, the flow rate of $60 \mathrm{~mL} / \mathrm{h}$ is considered the optimum inlet flow rate of the reactants.

Effect of organic co-solvent presence: The main obstacle facing methanolysis of the waste vegetable oil is the presence of two immiscible phases that slows the reaction significantly. In order to conduct the transesterification reaction in a single phase and facilitate

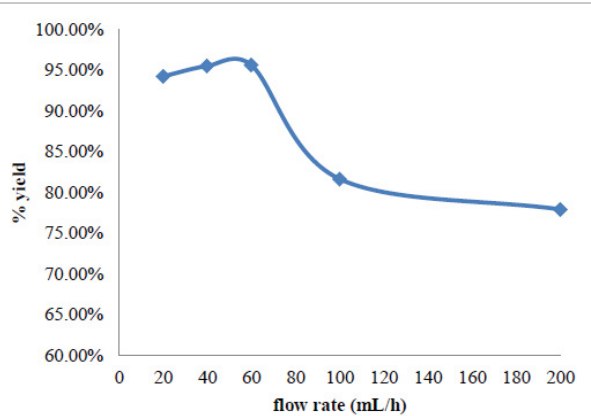

Figure 5: Effect of reactants flow rate on percentage biodiesel yield.

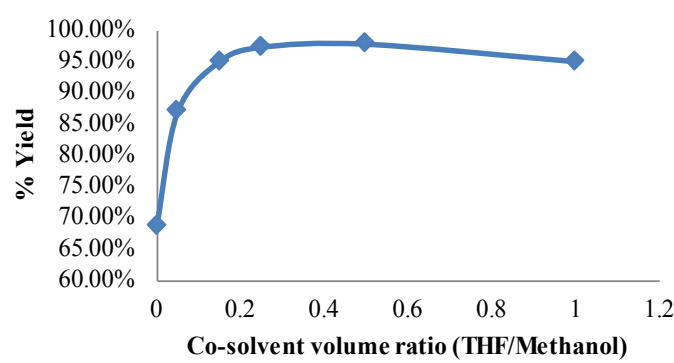

Figure 6: Effect of co-solvent volumetric ratio (THF/methanol) on percentage biodiesel yield.

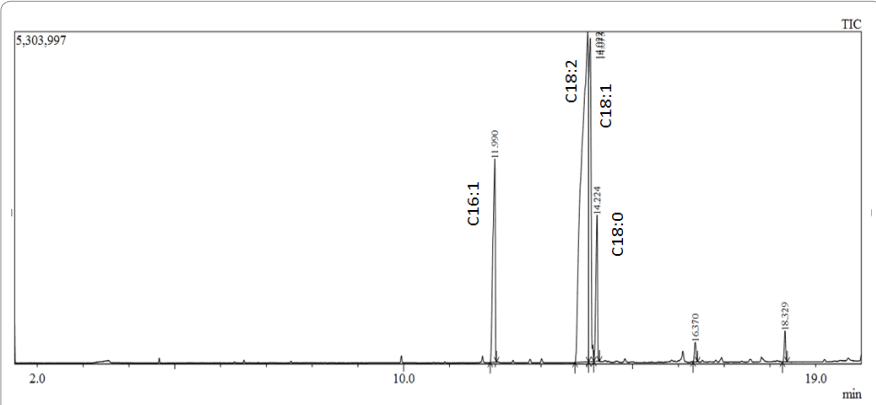

Figure 7a: Gas chromatography-mass spectrometry of biodiesel produced at optimum processing conditions using KM micro-mixer.

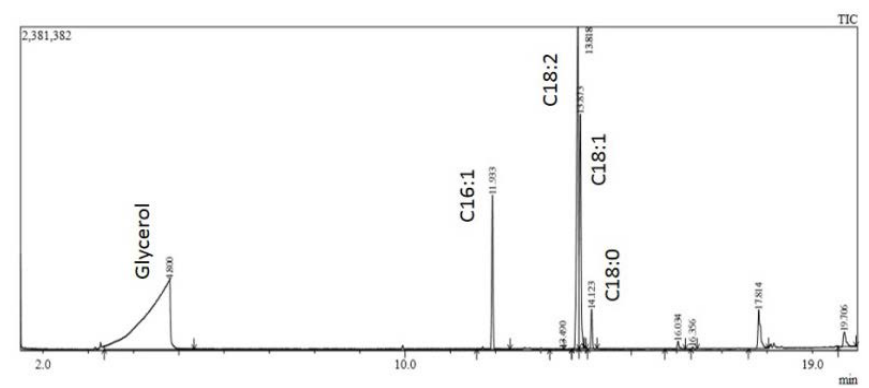

Figure 7b: Gas chromatography-mass spectrometry of biodiesel produced using 24:1 methanol: oil molar ratio. 
the diffusion of the two immiscible reactant fluids, an organic cosolvent has been suggested [4]. THF was preferable compared to other co-solvents because its boiling point is near to the boiling point of methanol that facilitates its separation from the excess methanol at the end of the reaction [4]. However, large amounts of THF are not favored to be used at the transesterification process regarding that the excess co-solvent may cause reagents dilution which declines the rate of transesterification process [19]. Moreover, using large THF amounts at the transesterification process increases the process cost aspects.

In this regards, the effect of presence co-solvent to methanol volumetric ratio on biodiesel production yield was examined over the studied range from 0.2 to 1 . It was indicated from Figure 6, noticeable improvement at the production yield using just small amount from THF to methanol ratio. Moreover, the biodiesel production yield was increased as the THF to methanol volumetric ratio increased. This behavior confirms the positive role of the co-solvent presence at the transesterification reaction. The optimum biodiesel production yield of 97.3\% was recorded using THF to methanol volumetric ratio of 0.3:1. As the utilized THF to methanol volumetric ratio increased above the optimum selected value, there is no noticeable enhancement at the biodiesel production yield.

\section{Characterization of produced biodiesel}

In order to investigate the properties of the produced biodiesel at the predetermined optimum conditions using $\mathrm{KM}$ micro-mixer, it was compared with its parent waste vegetable oil using different characterization techniques.

Gas chromatography-mass spectrometry: GC-MS was used for determination of biodiesel methyl ester groups present at the produced biodiesel using KM micro-mixer to determine the optimum conditions. Figure 7a showed GC-MS analysis of biodiesel produced at the optimum conditions using KM micro-mixer. There were four main characteristics peaks of fatty acid methyl esters (FAMEs) appearing by the retention time and the fragmentation pattern data of GC-MS analysis. These four peaks identified FAMEs as 9-hexadecanoic acid methyl ester (C16:1), 9, 12-Octadecadienoic acid methyl ester (C18:2), 9-Octadecenoic acid methyl ester (C18:1) and Octadecanoic acid methyl ester (C18:0). The identified FAMEs were verified by retention time data and mass fragmentation pattern from previous studies [20]. As previously discussed, the glycerol characteristics peaks were only present at the GC-MS analysis of the prepared biodiesel sample using excess methanol to oil molar ratio or at insufficient separation time conditions. Figure $7 \mathrm{~b}$ investigates GC-MS analysis of biodiesel sample produced at $48: 1$ methanol to oil molar ratio. It was clear the appearance of glycerol peak at 4.7 minutes retention time [21]. These results confirm the previous optimum selected conditions for biodiesel production using KM micro-mixer. Furthermore, GC-MS analysis of the produced biodiesel at optimum processing conditions confirms completeness of the transesterification process of triglycerides in the waste vegetable oil into biodiesel. The percentage conversion of triglycerides to the corresponding methyl esters from the GC-MS analysis of the optimum produced biodiesel was calculated as $98 \% \mathrm{wt}$ compared with $85 \%$ wt for the biodiesel prepared sample using excess methanol (48:1 molar ratio).

Thermal gravimetric analysis (TGA)7.3.1 Peak pressure: TGA analysis is one useful way for quantitative analysis for the produced biodiesel. It is well known that the biodiesel starts to thermally decompose at approximately $150^{\circ} \mathrm{C}$ and continues its thermal decomposition until complete vaporization. However, the waste vegetable oil begins its thermal degradation at approximately $350^{\circ} \mathrm{C}$. Accordingly, the percentage of biodiesel conversion at the prepared
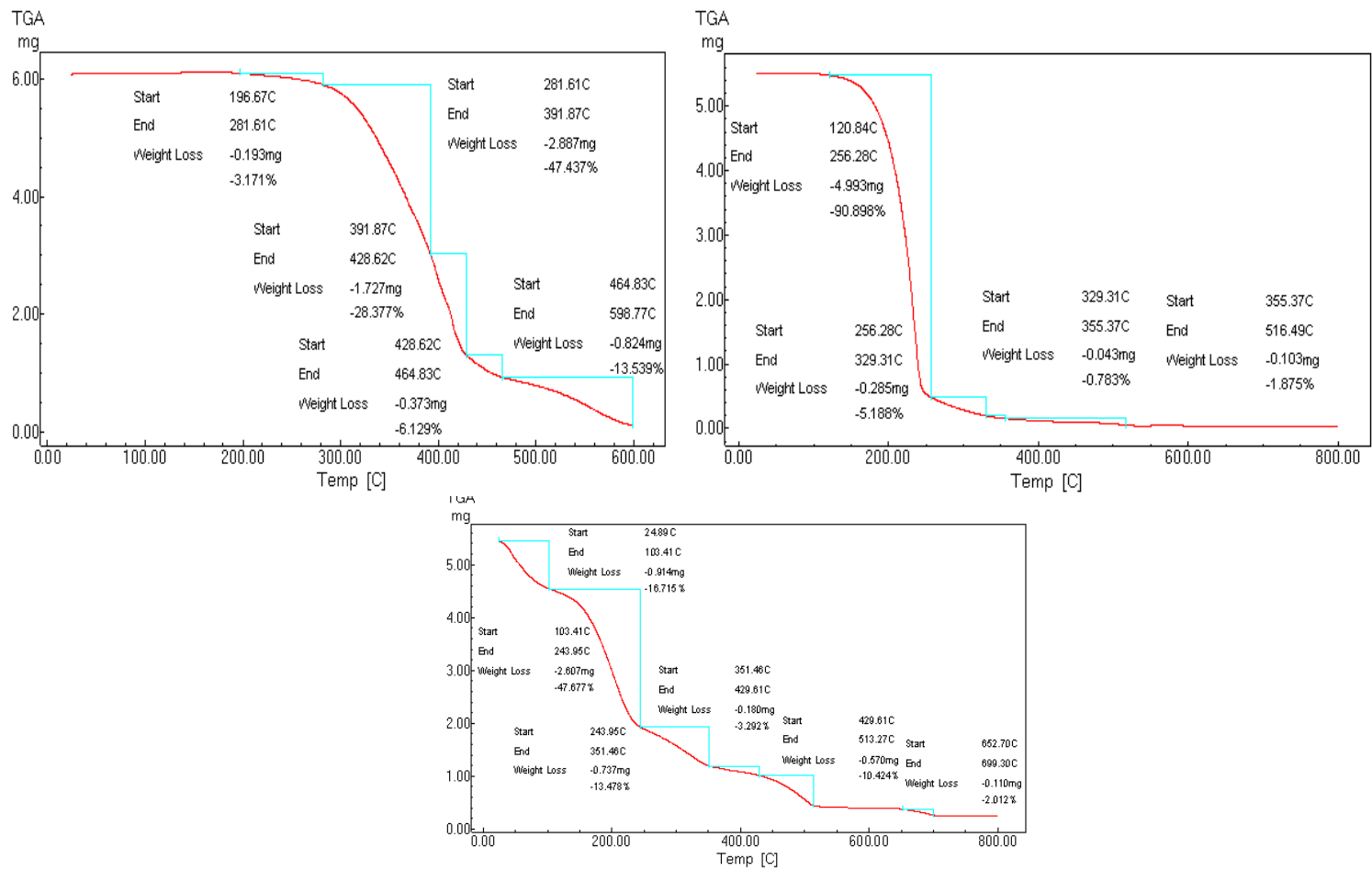

Figure 8: TGA diagram for waste vegetable oil. b. TGA diagram for Biodiesel produced at optimum conditions. c. TGA diagram for Biodiesel produced at high reactant flow rates. 


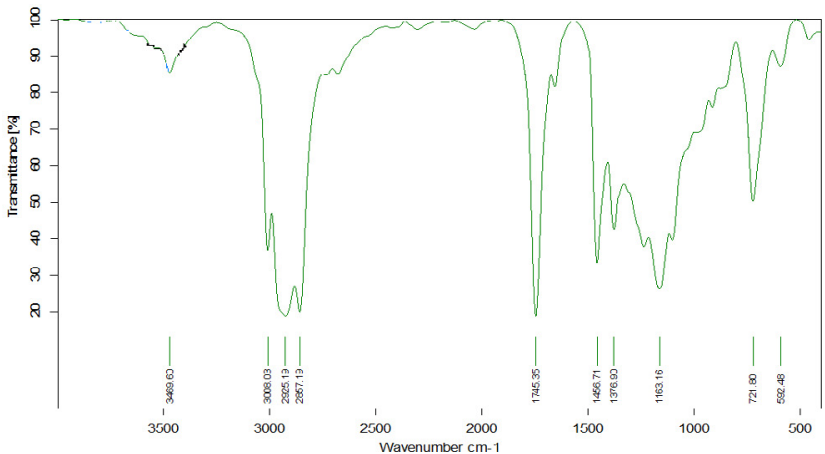

Figure 9a: FT-IR spectrum for waste vegetable oil.

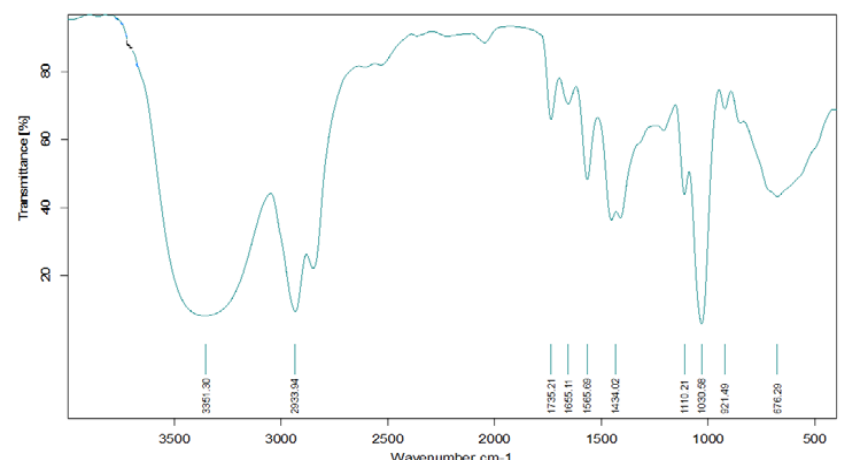

Figure 9b: FT-IR spectrum for biodiesel produced at optimum conditions.

sample may be calculated using TGA analysis [22]. The thermal gravimetric analysis of the biodiesel produced sample at optimum conditions using KM micro-mixer was compared with its parent waste oil and the biodiesel prepared sample using high inlet reactant flow rate of $200 \mathrm{~mL} / \mathrm{hr}$. Figure $8 \mathrm{a}$ clarifies that the parent vegetable oil starts its thermal degradation at approximately $300^{\circ} \mathrm{C}$ compared with $120^{\circ} \mathrm{C}$ for that other two biodiesel samples (Figure $8 \mathrm{~b}$ and c). Biodiesel completes vaporization at around $330^{\circ} \mathrm{C}$. The recorded over all percentage weight loss with in biodiesel degradation temperature range from $120^{\circ} \mathrm{C}$ to $330^{\circ} \mathrm{C}$ for the optimum biodiesel prepared sample (Figure $8 \mathrm{~b}$ ) was $96.5 \%$ compared with $60 \%$ weight loss for the biodiesel prepared sample at the high reactant flow rate of $200 \mathrm{~mL} / \mathrm{h}$ (Figure 8c). Moreover, it was indicated from Figure 8c that the biodiesel sample prepared at high reactant flow rates poses around 30\% weight losses within the oil degradation temperature range, explained as unreacted oil [23]. These results confirm the successful biodiesel production in pure state at the optimum preparation conditions in contrast to biodiesel prepared at high reactant flow rates that contains remaining unreacted oil. Accordingly, the TGA analysis results confirm the previous GC-MS analysis results.

Fourier transform Infrared spectroscopy FT-IR: FT-IR spectrometry is a rapid and precise method for quantification of FAME. FT-IR spectrometry identifies the main functional groups presence at both the optimum produced biodiesel sample and its parent waste vegetable oil [24].

The most characteristics absorption peaks of the waste vegetable oil were indicated at figure (9a). The absorption peak appearing at 721 $\mathrm{cm}^{-1}$ is representative to $-\mathrm{CH}_{2}$ rocking and the other one at $1745 \mathrm{~cm}^{-1}$ is representative to $\mathrm{C}=\mathrm{O}$ ester stretch. Figure $9 \mathrm{~b}$ showed the produced biodiesel absorption peaks appearing at $1434 \mathrm{~cm}^{-1}$ which is the methyl ester group $\left(\mathrm{CO}-\mathrm{O}-\mathrm{CH}_{3}\right)$ and the characterization peak at $1195 \mathrm{~cm}^{-1}$ corresponding to $(\mathrm{C}-\mathrm{O})$ ester peak. It was obvious the reduction of $\mathrm{CH}_{2}-\mathrm{O}$ - groups in oil and the appearance of $\mathrm{CH}_{3}-\mathrm{O}$ - vibrations in biodiesel. Also, the split of $1163 \mathrm{~cm}^{-1}$ in the oil sample into $1195 \mathrm{~cm}^{-1}$ and $1168 \mathrm{~cm}^{-1}$ in the biodiesel sample indicates the conversion of oil into biodiesel. The main difference between the two FTIR spectrums is related to the transformation of ester groups at the waste oil sample into methyl esters at the produced biodiesel [20].

\section{Conclusions}

This study investigated the use of $\mathrm{KM}$ micro-mixer in the production of biodiesel from waste vegetable oil. The effects of methanol/oil molar ratio, catalyst concentration, volumetric flow rates and the presence of a co-solvent on the transesterification reaction were examined. The study proved that the reaction can be completed giving higher percentage yield of biodiesel that reached $97 \%$. In order to characterize the biodiesel product, its quality and quantity, GC-MS analysis has shown the characteristic peaks of FAMEs that ranged between $\mathrm{C} 16-\mathrm{C} 18$ methyl esters as main products with $98 \%$ yield. In addition, TGA and FTIR analysis were used to differentiate between the produced biodiesel and its parent oil. The results from both GCMS and TGA methods were in good agreement regarding the quantity. The study confirms that the proposed KM micro-mixer designed with fourteen micro-channels was found effective for transesterification reaction completion. Thus, it can be employed in biodiesel production introducing many advantages over the batch reaction like time saving and higher yield and better conversion.

\section{References}

1. Alamu OJ, Waheed MA, Jekayinfa SO, Akintola TA (2007) Optimal transesterification duration for biodiesel production from Nigerian palm kernel oil. Agricultural engineering International CAIGE Journal 9: 1-11.

2. Demirbas A (2005) Biodiesel production from vegetable oils via catalytic and non-catalytic supercritical methanol transesterification methods. Progress in Energy and Combustion Science 31: 466-487.

3. Ali Y, Hanna M, Cuppett S (1995) Fuel properties of tallow and soybean oil esters. Journal of the American Chemical Society 72: 1557-1564.

4. Meher L, Vidyasagar D, Naik S (2006) Technical aspects of biodiesel production by transesterification-a review. Renewable and Sustainable Energy Reviews 10: 248-268.

5. Canakci M (2007) The potential of restaurant waste lipids as biodiese feedstocks. Bioresource Technology 98: 183-190.

6. Matha MC, Kumarb SP, Chettyc SV (2010) Technologies for biodiesel production from used cooking oil -A review. Energy for Sustainable Development 14: 339 345

7. Singh A, He B, Thompson J, van Gerpen J (2006) Process optimization of biodiese production using different alkaline catalysts. Appl Eng Agr 22: 597-600.

8. Šalić A, Zelić B (2011) Microreactors portable factories for biodiesel fue production. gorivaimaziva (fuels and lubricants journal) 2: 85-110.

9. Gude VG, Grant GE (2013) Biodiesel from waste cooking oils via direct sonication. Applied Energy 109 135-144.

10. Xie T, Zhang L, Xu N (2012) Biodiesel synthesis in microreactors. Green Process Synthesis 1: 61-70.

11. Noureddini H, Zhu D (1997) Kinetics of transesterification of soybean oil. Journal of the American Oil Chemists' Society 74: 1457-1463.

12. Kobayashi J, Mori Y, Kobayashi S (2006) Multiphase organic synthesis in microchannel reactors. Chem. Asian J 1: 22-35.

13. Wen Z, Yu X, Tu ST, Yan J, Dahlquist E (2009) Intensification of biodiese synthesis using zigzag micro-channel reactors. Bioresource Technology 100 3054-3060.

14. Nagasaw H, Aoki N, Mae K (2005) Design of a new micromixer for instant 
Citation: Elkady MF, Zaatout A, Balbaa O (2015) Production of Biodiesel from Waste Vegetable Oil via KM Micro-mixer. J Pet Environ Biotechnol 6: 218. doi: $10.4172 / 2157-7463.1000218$

Page 7 of 7

mixing based on the collision of micro segments. Chemical engineering \& technology 28: 324-330.

15. Kulkarni MG, Dalai AK (2006) Waste cooking oil-an economical source for biodiesel: a review. Industrial and Engineering Chemistry Research 45: 29012913.

16. Bournay L, Casanave D, Delfort B, Hillion G, Chodorge JA (2005) New heterogeneous process for biodiesel production: A way to improve the quality and the value of the crude glycerin produced by biodiesel plants. Catalysis Today 106: 190-192.

17. Vyas AP (2011) Effects of Molar Ratio, Alkali Catalyst Concentration and Temperature on Transesterification of Jatropha Oil with Methanol under Ultrasonic Irradiation. Advances in Chemical Engineering and Science 1: 45-50.

18. Kumar D, Kumar G, Singh CPP (2010) Ultrasonic-Assisted Transesterification of Jatropha curcus Oil Using Solid Catalyst, $\mathrm{Na} / \mathrm{SiO}_{2}$. Ultrasonics Sonochemistry 17: 839-844

19. Encinar JM, Gonzalez JF, Pardal A, Martinez G (2010) Transesterification of Rapeseed oil with methanol in the presence of carious co-solvents,
Proceedings. Venice Third International Symposium on Energy from Biomass and Waste Venice 8: 839-844.

20. Tariq M, Ali S, Ahmad F, Ahmad M, Zafar M et al. (2011) Identification, FT-IR NMR $\left({ }^{1} \mathrm{H}\right.$ and $\left.{ }^{13} \mathrm{C}\right)$ and $\mathrm{GC} / \mathrm{MS}$ studies of fatty acid methyl esters in biodiesel from rocket seed oil. Fuel Processing Technology 92: 336-341.

21. McCurry JD (2011) Automation of a Complex, Multi-Step Sample Preparation Using the Standalone Agilent 7696A Work Bench. Agilent Technologies Publication Number 5990-7525EN.

22. Chand P, Reddy V, Verkade G, Wang T, Grewell D (2009) Thermogravimetric Quantification of Biodiesel Produced via Alkali Catalyzed Transesterification of Soybean oil. Energy and Fuels 23: 989-992.

23. Hamze H, Akia M, Yazdani F (2015) Optimization of biodiesel production from the waste cooking oil using response surface methodology. Process Safety and Environmental Protection 94: 1-10.

24. Oliveira JS, Montalvão R. Daher L, Suarez PAZ, Rubim JC (2006) Determination of methyl ester contents in biodiesel blends by FTIR-ATR and FTNIR spectroscopies. Talanta 69: 1278-1284. 